oral cavity volume to accommodate the tongue, preventing tongue compression and swelling. Perhaps dentures should not be too far removed from their edentulous owners.

E.H.C. Liu MBCHB FRCA

W.K.S. Tan BDS

H.L. Pua MBbs Mmed (Anaesth)

Singapore

References

1 Vogel JE, Mulliken JB, Kaban LB. Macroglossia: a review of the condition and a new classification. Plast Reconstr Surg 1986; 78: 715-23.

2 Cohen AM, Vig PS. Lateral tongue spreading. J Dent $1973 ; 2: 32-4$.

\section{Reversal of ECG signs of ischemia}

To the Editor:

We would like to present the disappearance of angina and of the ECG signs of ischemia following a thoracic epidural injection of ropivacaine. A 57-yr-old woman known for refractory angina for ten months was referred to the department of anesthesia for repeated chemical thoracic sympathectomy. Her ECG showed inverted ' $\mathrm{T}$ ' waves in all derivations (Figure 1). After a difficult, and probably failed, technique of left stellate ganglion block, she presented with intense chest pain with pseudonormalization of her ECG, indicating acute myocardial ischemia (Figure 2). ${ }^{1}$ Medical treatment with nitrates and nifedipine was unsuccessful. A continuous thoracic epidural block was then performed at the $\mathrm{T}_{3-4}$ interspace and $5 \mathrm{ml}$ ropivacaine $2 \%$ were injected into the epidural space. The chest pain

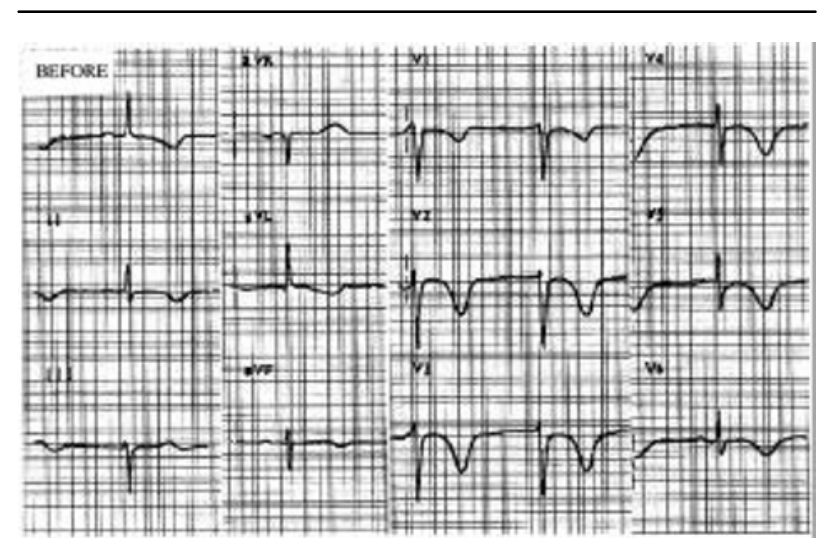

FIGURE I Basic ECG aspect before apparition of acute anginal pain.

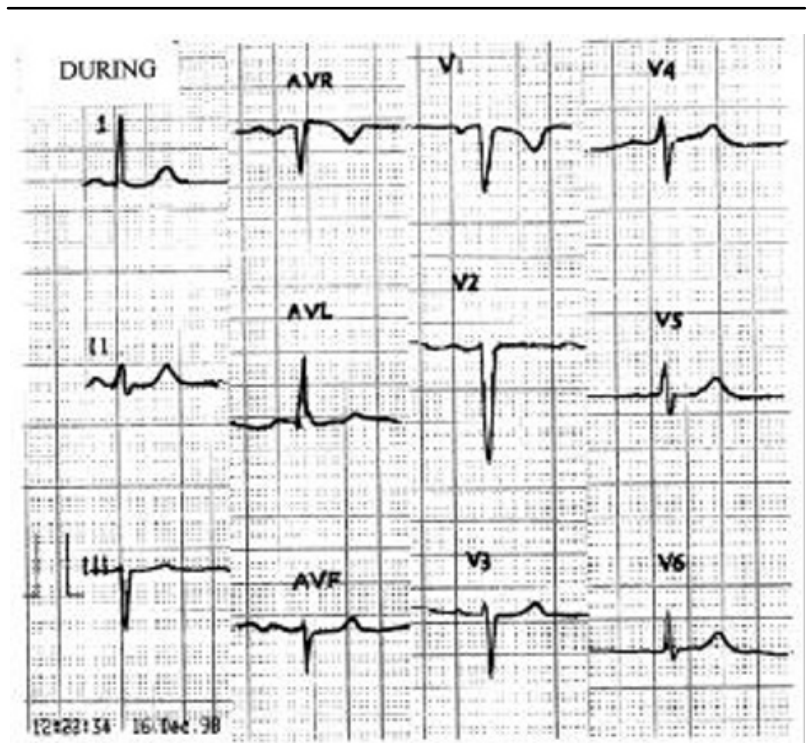

FIGURE 2 ECG aspect during acute anginal pain (pseudonormalization phenomenon).

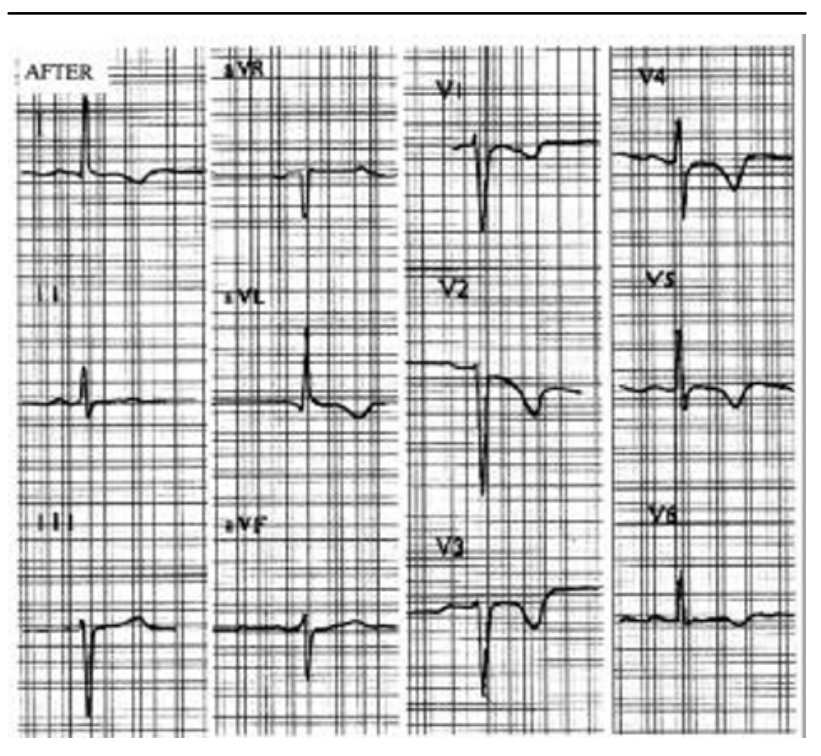

FIGURE 3 ECG aspect after disappearance of acute anginal pain following thoracic epidural anesthesia.

disappeared very soon after, with the ECG coming back to its pre-stellate ganglion block aspect (Figure $3)$. The epidural catheter was left in place for $24 \mathrm{hr}$, with two $4 \mathrm{ml}$ prophylactic injections of ropivacaine. Thoracic epidural block have been advocated as the last option for the treatment of angina before coronary 
artery bypasss surgery, ${ }^{2}$ and stellate ganglion block has been reported to improve intractable angina. ${ }^{3}$ The present observation of symptomatic improvement of angina with corresponding ECG changes following thoracic injection of ropivacaine may be another observation of the effect of a sympathetic blockade on coronary circulation, may be through a myocardial blood flow redistribution mechanism. ${ }^{4,5}$

Pierre Léna MD

René Martin MD

Philippe Durand MD

St Laurent du Var, France

Sherbrooke, Canada

\section{References}

1 Hutter $A M$. Ischemic heart disease: angina pectoris. In: Rubenstein E, Federman DD (Eds.). Scientific American Medicine. New York: Scientific American Inc., 1995: 1 card, IX-4.

2 Overdyk FJ, Gramling-Babb PM, Handy JR Jr, Faller NI, Miller MJ. Thoracic epidural anesthesia as the last option for treating angina in a patient before coronary artery bypass surgery. Anesth Analg 1997; 84: 213-5.

3 Leach $A$. Old ideas, new applications (Editorial). $\mathrm{Br} \mathrm{J}$ Anaesth 1998; 81: 113-5.

4 Klassen GA, Bramwell RS, Bromage PR, ZborowskaSluis DT. Effect of acute sympathectomy by epidural anesthesia on the canine coronary circulation. Anesthesiology 1980; 52: 8-15.

5 Tsuchida $H$, Omote T, Miyamoto M, Namiki A, Ichibara K, Abiko Y. Effects of thoracic epidural anesthesia on myocardial $\mathrm{pH}$ and metabolism during ischemia. Acta Anesthesiol Scand 1991; 35: 508-12. 